\title{
Disputas político-econômicas em torno da democratização educacional brasileira no século XXI
}

\author{
Carlos Felipe Nunes Moreira ${ }^{1}$ \\ https://orcid.org/0000-0001-7294-149X \\ ${ }^{1}$ Universidade do Estado do Rio de Janeiro, Faculdade de Serviço Social, Rio de Janeiro, RJ, Brasil.
}

\begin{abstract}
Disputas político-econômicas em torno da democratização educacional brasileira no século XXI
Resumo: O objetivo do texto é refletir se, atualmente, a prática social em defesa da política de educação no Brasil, sob as atuais condições impostas pelo capitalismo, adquire ou não um novo sentido crítico e contornos anticapitalistas. Para tal, é apresentado um breve resgate histórico das principais lutas sociais travadas neste século ligadas à educação no País, sustentado pelo diálogo com autores filiados à tradição marxista. Os resultados apontam para a necessidade de maior aprofundamento no que tange ao processo de solidificação de um projeto educacional antagônico, articulado com o movimento de superação da ordem capitalista, no qual o Serviço Social tem como compromisso ético inserir-se e fortalecê-lo, orientado por uma concepção ampliada de democracia.
\end{abstract}

Palavras-chave: Educação. Capitalismo. Poder político-econômico. Socialização do poder. Democratização da política educacional.

Political and Economic Disputes over Brazilian Educational Democratization in the 21st Century Abstract: This article discusses whether the social practice in defense of education policy in Brazil, under the current conditions capitalism imposes, acquires a new critical sense and anti-capitalist features. A brief historical review of the main social struggles in education of this century in Brazil is presented, supported by a dialogue with Marxist authors. The results point to the need for further research on the process of consolidation of an antagonistic educational project, coordinated with the movement of overcoming the capitalist order. The social work has the ethical commitment to be part of this educational project and strengthen it, led by an expanded concept of democracy.

Keywords: Education. Capitalism. Political and economic power. Socialization of power. Democratization of educational policy.

Recebido em 01.02.2019. Aprovado em 16.04.2019. Revisado em 19.06.2019.

(C) O(s) Autor(es). 2019 Acesso Aberto Esta obra está licenciada sob os termos da Licença Creative Commons Atribuição-NãoComercial 4.0 Internacional (https://creativecommons.org/licenses/by-nc/4.0/deed.pt_BR), que permite copiar, distribuir e reproduzir em qualquer meio, bem como adaptar, transformar e criar a partir deste material, desde que para fins não comerciais e que você forneça o devido crédito aos autores e a fonte, insira um link para a Licença Creative Commons e indique se mudanças foram feitas. 


\section{Introdução}

A premissa teórica deste estudo reside no entendimento de que o fundamento ontológico do debate sobre a democratização da política de educação se localiza na relação orgânica entre política e economia, na qual a socialização do poder político constitui mediação central. Formalmente, a gestão democrática do ensino público no Brasil é garantida por lei. Por outro lado, após quase uma década de experiência profissional como assistente social em escolas municipais do Rio de Janeiro, a observação teórico-prática pessoal revela uma educação escolarizada autoritária, centralizadora, estratificada socialmente e marcada por forte racionalidade empresarial, na qual os princípios e valores da democracia liberal-burguesa e neoliberal tendencialmente prevalecem.

O modo como o Estado brasileiro responde às expressões da questão social relacionadas à educação formal é através de um projeto burguês historicamente caracterizado por uma política estreita às exigências produtivas de um País de capitalismo periférico e dependente que ingressou na fase monopolista do capital somente na metade do século passado. O posicionamento do Brasil na dinâmica econômica mundial vem exigindo da força de trabalho nacional uma formação voltada para atender, sobretudo, as requisições imediatas do trabalho necessário vinculado ao modo particular da industrialização brasileira.

As lutas sociais por uma educação pública, gratuita, universal, democrática e de qualidade têm se confrontado permanentemente contra uma política educacional que, se por um lado, avançava lentamente nas conquistas liberal-democráticas no plano legal, por outro, não se consubstanciou em sua totalidade no plano da realidade concreta. A interpretação que se pode atribuir a tal fenômeno é que para a expropriação dual do excedente econômico, a formação educacional precarizada da classe trabalhadora das periferias do sistema é necessária para a redução dos custos com o capital variável e suficiente para a garantia da realização da maisvalia. Nesse sentido, através de um consenso autoritário e do poder garantido pela concentração políticoeconômica, é que se localizam a resistência que as elites dirigentes brasileiras opõem à manutenção da educação pública e prega sua contínua descontinuidade.

Partindo da constatação de que o trabalho conforma a base ontológica da categoria educação, os diferentes modos de produção ao longo da história organizaram seu aparato educacional de modo a privilegiar as classes sociais detentoras do poder político-econômico, mantendo a distinção entre dominantes e dominados combinada com o tipo de educação destinada a cada um desses segmentos. No capitalismo, diante a exigência de universalização da produção social, a generalização de instituições sociais potencialmente capazes de capilarizar os valores culturais e intelectuais hegemônicos é parte inerente do processo de conformação da política de educação e das escolas, tal como se apresentam no Brasil do século XXI.

Este artigo trabalha a política educacional condicionada à concentração do poder político-econômico burguês, investigando se a luta social em defesa da política de educação no Brasil, sob as atuais condições impostas pelo capitalismo, adquire ou não um novo sentido crítico e contornos anticapitalistas. Debate indispensável às análises do trabalho profissional de assistentes sociais na educação quando orientado pelo projeto ético-político do Serviço Social. Para tanto, são considerados os fundamentos ontológicos da categoria educação, suas relações com a esfera do trabalho e da reprodução social, as particularidades da função social que a educação adquire na sociedade do capital enquanto política social e suas determinações no capitalismo brasileiro contemporâneo.

\section{Principais expressões das lutas sociais na disputa pela democratização da política de educação no Brasil contemporâneo}

Na última virada de século, o agravamento da crise econômica fez abalar a coesão política entre frações da burguesia brasileira que assistiram, no plano geral da luta de classes, o aumento no número de greves e das lutas sociais, alcançando níveis considerados temerários pelos setores dominantes. Considerando que no pleito eleitoral de 2002 o Partido dos Trabalhadores (PT) já havia modificado em profundidade sua agenda política, é legítimo afirmar que - permeado por importantes contradições - o País adentrou uma fase seguinte da contrarrevolução preventiva e prolongada a fria (FERNANDES, 2006).

No balanço crítico que Frigotto (2011) elabora acerca da política educacional na primeira década dos anos 2000, o autor aponta que inaugura-se uma nova conjuntura com a presidência de Lula da Silva, considerando que "[...] as forças sociais progressistas que conduziram ao poder o atual governo tinham, em sua origem, a tarefa de alterar a natureza do projeto societário, com consequências para todas as áreas" (FRIGOTTO, 2011, p. 237). Contudo, o caminho trilhado pelo PT foi - orientado pelo pacto social de conciliação capitaltrabalho - o do desenvolvimentismo comprometido com a programática neoliberal já em andamento, porém com diferenciações ${ }^{1}$ em relação ao período anterior. Nesse sentido: 
[...] ao não disputar um projeto societário antagônico à modernização e ao capitalismo dependente e, portanto, à expansão do capital em nossa sociedade, centrando-se num projeto desenvolvimentista com foco no consumo e, ao estabelecer políticas e programas para a grande massa de desvalidos, harmonizandoas com os interesses da classe dominante [...], o governo também não disputou um projeto educacional antagônico, no conteúdo, no método e na forma. (FRIGOTTO, 2011, p. 241, grifo nosso).

A reconfiguração da base produtiva centrada em medidas a favor do setor de commodities - e ainda pelo ineditismo na internacionalização das corporações deste ramo localizadas no País, acentuando a relação de dependência brasileira - repercutiu diretamente no planejamento do perfil educacional determinado pelo "[...] ethos por práticas educativas "interessadas" e alienantes" necessário ao padrão de acumulação (LEHER, 2010, p. 55). O caráter focalista atribuído às respostas das expressões da questão social, marcante nas políticas sociais nos anos 2000, também se mostrou presente na política de educação do período. Orientada pela ideologia que vislumbra no dualismo educacional uma via para as chamadas inclusão social e empregabilidade das frações pauperizadas da classe trabalhadora, a política de educação nos governos do PT reforçou - a partir de uma estrutura que se difere da anterior principalmente em sua aparência - a formação tecnológica desvinculada da educação geral.

Com isso, o Estado, em vez de alargar o fundo público na perspectiva do atendimento a políticas públicas de caráter universal, fragmenta as ações em políticas focais que amenizam os efeitos, sem alterar substancialmente as suas determinações. E, dentro dessa lógica, é dada ênfase aos processos de avaliação de resultados balizados pelo produtivismo e à sua filosofia mercantil, em nome da qual os processos pedagógicos são desenvolvidos mediante a pedagogia das competências. (FRIGOTTO, 2011, p. 245, grifo nosso).

Mistificada pela ideia de ampliação da oferta e de democratização do acesso, a massificação mercantil do ensino superior se intensificou deste período em diante. Conduzida por fortes incentivos tributários por parte do Estado e em conformidade com o padrão compósito de hegemonia burguesa, a expansão quantitativa nos setores público ${ }^{2}$ e privado ${ }^{3}$ seguiu a lógica da crescente internacionalização da educação superior nos moldes previstos pela Organização Mundial do Comércio - especialmente por meio de cursos a distância - e contou (tal como durante a ditadura civil-militar e reforçando a premissa do imperialismo total) com a assessoria da United States Agency for International Development.

Segundo Leher (2010), as principais medidas para o ensino médio negaram os parâmetros defendidos pelo Congresso Nacional de Educação (CONED) e os fundamentos da politecnia e da escola unitária, uma vez que seus conceitos se revelam incongruentes com o padrão de acumulação capitalista dependente que se aprofunda no País. Para Frigotto (2011), no plano geral da política educacional e sem corroborar o discurso da mera continuidade, a lógica vigente na década de 1990 define hegemonicamente a primeira década do século XXI, reafirmando as parcerias público-privadas e ampliando a dualidade estrutural da educação, "[...] abrangendo desde o conteúdo do conhecimento até os métodos de sua produção ou socialização" (FRIGOTTO, 2011, p. 242). A nova dinâmica da influência empresarial, “[...] sem paralelo na história da educação brasileira [...]" (LEHER, 2010, p. 56), significou a incidência orgânica das agências do capital sobre a educação de maneira inédita, em sintonia fina com os princípios neoliberais presentes na agenda do Banco Mundial.

A cooptação de importantes movimentos sociais promovida pelo governo e a consequente restrição do potencial de resistência política da sociedade civil aceleraram a produção do consenso ativo e passivo em relação às tais investidas do capital no âmbito educacional, isolando as reivindicações de caráter anticapitalista somente àquelas entidades que se mantiveram autônomas. "Com efeito, as forças mais à esquerda do FNDEP4 buscavam retomar as proposições do PNE: Proposta da Sociedade Brasileira ${ }^{5}$ como contraponto às medidas governamentais. Assim, as tensões internas no Fórum tornaram-se mais relevantes" (LEHER, 2010, p. 57 , grifo do autor). Setores dirigidos por correntes que compunham a base do governo passaram a temer que o CONED pudesse aprovar resoluções abertamente críticas aos rumos da educação no governo e buscaram inviabilizar a convocação do Congresso. Mas, "[...] para isso, teriam de tomar uma decisão radical e de enorme consequência para a educação pública brasileira: desmontar o FNDEP” (LEHER, 2010, p.57). Assim:

Com a CUT ocupando o ministério do trabalho [...] - e dirigida pela força majoritária do PT -, a antiga unidade de ação dos sindicatos do serviço público começou a ser desfeita, situação que se agravou na educação. Os sindicatos dirigidos pelas correntes da base governista, em especial do PT e do PCdoB, como a Confederação Nacional dos Trabalhadores da Educação (CNTE), Confederação Nacional dos Trabalhadores em Estabelecimentos de Ensino (Contee) e parte da Federação dos Sindicatos dos Trabalhadores das Universidades Públicas Brasileiras (Fasubra Sindical), bem como da direção majoritária da UNE, lograram desfazer o FNDEP, intento concluído no Fórum Social Mundial (FSM) de 2005. O motivo 
alegado para isso foi que não havia mais acordo com determinados eixos e princípios do PNE: Proposta da Sociedade Brasileira. (LEHER, 2010, p. 57, grifo do autor).

Entretanto, no lugar dos sindicatos e demais movimentos sociais da base do governo influenciarem na definição das orientações e nas medidas concretas para a política de educação - a partir da difundida ideia dicotômica e enviesada de que se tratava de um governo em disputa e polarizado pelas áreas econômica e social -, foram os setores empresariais que lograram maior influência. O Plano de Desenvolvimento da Educação (PDE), instituído por decreto e com ascendência sistêmica dos representantes do capital, "[...] silenciou a problemática do veto aos $7 \%$ do PIB para a educação pública ${ }^{6}$ e instituiu diversos programas fragmentados". Uma fragmentação que ampliou a subordinação da educação à agenda dos setores dominantes por meio da “[...] neofilantropia empresarial [...]" (LEHER, 2010, p. 58) protagonizada no Brasil por instituições como: Fundação Roberto Marinho, Instituto Ayrton Senna, Fundação Victor Civita e Grupo Gerdau, dentre outras (LEHER, 2010). Para Frigotto (2011, p. 242, grifo do autor):

A junção da fragmentação ao abandono do campo crítico na disputa pelo projeto educativo e o foco de atendimento da grande massa desorganizada e despolitizada resultou naquilo que foi dominante na educação durante a década - a política da melhoria mediante as parcerias do público e privado.

Como desfecho, ainda de acordo com o autor (FRIGOTTO, 2011), reiteraram-se reformas que alteram aspectos da política educacional sem modificar a herança histórica brasileira que não garante a educação de igual qualidade como um direito universal. Algo "[...] desnecessário para o projeto modernizador e de capitalismo dependente aqui viabilizado" (FRIGOTTO, 2011, p. 242). No âmbito da sociedade civil, aparelhos privados de hegemonia de relação orgânica com as instituições do capital supracitadas ampliaram, neste contexto de parcerias público-privadas, sua força política e potencial organizativo. Dentre os principais, encontram-se as organizações de compromisso empresarial conhecidas como Amigos da Escola, Compromisso Todos pela Educação, Revista Nova Escola e, mais recentemente e em um polo à extrema direita, o movimento Escola sem Partido.

Tendo por objetivo oficial, segundo $\mathrm{Nagib}^{7}$ (apud ALGEBAILE, 2017, p. 64), “[...] dar visibilidade à instrumentalização do ensino para fins políticos, ideológicos e partidários [...] nos aspectos relacionados à educação moral, sexual e religiosa", a organização Escola sem Partido se autointitula como um movimento que engloba estudantes e familiares "[...] preocupados com o grau de contaminação político-ideológica das escolas brasileiras, em todos os níveis: do ensino básico ao superior". Principalmente através de um portal eletrônico ${ }^{8}$, o coletivo veicula suas ideias e procedimentos de vigilância, controle e criminalização daqueles profissionais de educação e materiais didáticos avaliados como de práticas e caráter doutrinário.

Sua visibilidade tem ganhado maior projeção social através da inserção de materiais de opinião em diversos meios de comunicação, da realização de debates e audiências nos âmbitos acadêmico, jurídico, religioso e parlamentar e pelo fomento de projetos de lei (ALGEBAILE, 2017). Neste último insere-se o PL 7180/ 2014 (BRASIL, 2014) que - antes de ser arquivado pela Câmara dos Deputados no final de 2018 - visava incluir, entre as diretrizes e bases da educação nacional, o Programa Escola sem Partido ${ }^{9}$. Mistificando o caráter político inerente e indissociável da prática educativa, o projeto (chamado de Lei da Mordaça pelas vertentes críticas) propunha, por exemplo, em seu Art. 2, inciso I, que a educação nacional atenderá a princípios como neutralidade política e ideológica. Fica nítido que:

[...] o objetivo [...] do movimento Escola sem Partido não é enfrentar possíveis excessos no processo pedagógico. É, na verdade, a garantia de um pensamento único nas salas de aula, mantendo a intensa hegemonia ideológica neoliberal [...] atual ainda mais blindada a riscos de questionamentos e disputas no sentido da necessária emancipação humana [...]. Em outras palavras: o objetivo é frear, de modo brusco, os processos de construção e de fortalecimento de uma educação contra-hegemônica que já se encontram em curso em diversas escolas brasileiras. (MOREIRA; RUIZ, 2016).

O ideário subjacente ao Escola sem Partido - também presente, mas diluído e/ou mistificado, nos demais movimentos anteriormente referidos - trata-se de uma "[...] ameaça à vivência social e à liquidação da escola pública como espaço de formação humana, firmado nos valores da liberdade, de convívio democrático e de direito e respeito à diversidade", de acordo com a avaliação de Frigotto (2017, p. 17). Para o autor, as teses do movimento precisam ser analisadas na mediação com o processo autoritário e elitista de formação sócio-histórico brasileiro e entendidas como algo que afeta a sociedade de uma maneira geral, em uma fase histórica de maior criminalização de movimentos sociais e políticos da esquerda e de recrudescimento do moralismo, da cultura do medo e da violência. 
Saviani (2016, p. 391) ainda acrescenta que, na atual fase de profunda crise capitalista, "[...] a classe dominante, não podendo se impor racionalmente, precisa recorrer a mecanismos de coerção no plano da sociedade política combinados com iniciativas de persuasão no plano da sociedade civil [...]" envolvendo os meios de comunicação e a investida coercitiva junto à educação escolar. Como bem afirma Audi (2018), não se trata somente de uma questão ideológica. A "[...] lei que propõe abordagens 'neutras', como tratar a ditadura militar brasileira como 'contra-revolução democrática de 31 de Março de 1964', e sem educação sexual para livrar salas de aula de 'doutrinação de esquerda', também envolve dinheiro" (AUDI, 2018). Desvelando a dimensão econômica do projeto - bem como a relação orgânica entre política e economia Audi (2018) ressalta que, "[...] além de satisfazer a onda conservadora que varre o país, o Escola Sem Partido também será uma ótima oportunidade de negócio para empresas de educação, sejam elas escolas ou editoras que imprimem livros didáticos".

Em cenário marcado pela diminuição do capital produtivo e pelo aumento do mercado informal de trabalho (com impactos diretos na arrecadação do Estado), as ações do Escola sem Partido inserem-se em um processo político regressivo mediado pelas necessidades econômicas de retomada da taxa de lucros de setores gerais e particulares, pelas políticas de austeridade e de ajustes junto ao capital variável e às políticas sociais. Lógica na qual também se enquadra a consumação do golpe institucional de $2016^{10}$. Assim:

As forças e intelectuais que as promovem são a expressão política e ideológica do contexto atual, que assumem as relações sociais capitalistas no Brasil. [...] A relação entre os mecanismos jurídicos formais que sustentaram [...] o golpe e as teses do Escola sem Partido de incriminar os docentes tem na delação, com base no arrependimento ou discordância moral, seu fundamento mais ardiloso e perverso [...]. (FRIGOTTO, 2017, p. 25-30, grifo do autor).

A nova conjuntura iniciada com as chamadas jornadas de junho de 2013 e com a consumação do movimento de impeachment de Dilma Rousseff apresentou mudanças nos modos de concentração do poder político-econômico, no qual a dimensão do consenso se contrai, ampliando sua impermeabilização em relação às reivindicações dos trabalhadores diante o acelerado desmonte dos direitos sociais, enquanto a perspectiva coercitiva socialmente se alarga. É neste contexto histórico que vislumbramos a contrarreforma do ensino médio - via Medida Provisória decretada sem diálogo prévio com a sociedade civil - que implicou na redução da sua carga horária total a partir da conjunção de uma base comum $^{11} \mathrm{e}$ um itinerário formativo que coloca em um plano de importância secundária disciplinas como sociologia, filosofia, artes e educação física, pondo-se na "[...] contramão da luta pelo acesso ao conteúdo historicamente produzido pela humanidade, de uma formação ampla e profunda, que contemple arte, matemática, literatura, ciências da natureza, pensamento crítico etc.". (MORAES, 2016).

Pelo novo regramento firmado a partir da Lei no 13.415/2017 (BRASIL, [2017]), parte da formação do alunado poderá ocorrer através da realização de experiência prática de trabalho no setor produtivo, estabelecendo parcerias para o cumprimento de exigências curriculares. Ou seja, o estudante, ao invés de cumprir toda a carga horária na escola, poderá também cumpri-la oferecendo sua força de trabalho a baixo custo para o capital ou voluntariamente no setor privado, elevando a outro patamar a separação entre educação propedêutica e formação profissional em uma versão moderna das corporações de ofício do período pré-capitalista.

Além disso, conteúdos cursados pelos estudantes durante o ensino médio poderão ser convalidados para aproveitamento de créditos no ensino superior, o que corresponde ao exponenciamento do "[...] aligeiramento da formação em ambos os graus, para entregá-los ao mercado mais rapidamente. Esse aligeiramento também aparece com a "possibilidade de concessão de certificados intermediários de qualificação para o trabalho" (MORAES, 2016). Um apressuramento, já identificado em normativas anteriores, que levou Saviani (1989, p. 65) a afirmar que "o ensino das camadas populares pode ser aligeirado até o nada, até se desfazer em mera formalidade". A obrigatoriedade do estudo da história e cultura afro-brasileira e indígena ${ }^{12}$ passa, por sua vez, a ser tratada oficialmente no ensino médio como algo que deverá ser harmonizado à Base Nacional Comum Curricular. Para Moraes (2016):

Um dos pontos mais graves [...] diz respeito ao fato de que não será mais necessário ter formação em licenciatura para lecionar. Poderão ministrar conteúdos "profissionais com notório saber reconhecido pelos respectivos sistemas de ensino". Isso implica que os ideários empresariais e religiosos, por exemplo, poderão adentrar as escolas pela porta da frente e ocupar boa parte da grade curricular.

Na avaliação do Fórum Nacional de Educação, o governo de Michel Temer errou no método e no processo, ao impedir o debate e o encaminhamento adequado da matéria, errando ainda "[...] no conteúdo e suas 
repercussões no país, o que gerará mais atrasos e retrocessos em face da necessária formulação e implementação de medidas consistentes e bem fundamentadas para o Ensino Médio" (SAVIANI, 2016, p. 390).

Vale destacar que o Fórum Nacional de Educação (FNE) - entidade formada, após a Conferência Nacional de Educação (Conae) de 2010, com vistas à interlocução entre a sociedade civil e o Estado e à ampliação da democratização da gestão da política educacional em âmbito nacional, junto ao Ministério da Educação (MEC) e ao Conselho Nacional de Educação (CNE) ${ }^{13}$ - sofreu forte ataque político do governo Temer, via Portaria $n^{\circ} 577 / 2017$, que, dentre outras consequências, retirou sua responsabilidade com a organização da Conae (desrespeitando o regimento interno do Fórum) e destitui assento de associações históricas do campo da pesquisa em Educação. Assim, restringiu-se a participação das atuais representações, excluiu-se entidades representativas de segmentos essenciais e, na prática, promoveu-se a dissolução do FNE.

A nova fase do privatismo e da certificação em larga escala na educação nacional revela a atual face das disputas entre concepções antagônicas de educação pública e gratuita. O arrefecimento da educação escolar no nível médio agudiza a desigualdade historicamente impressa no direito à educação universal de qualidade no Brasil, adequa a baixa formação intelectual às condições do trabalho socialmente necessário em tempos de recessão econômica e ataca a capacidade organizativa dos trabalhadores em educação.

Para tal, promove-se a desprofissionalização da ativi-

\section{A desigualdade do poder}

\section{das instituições educacionais e}

da política de educação

contém em si a substância

para converter-se em

\section{resistência e em reivindicação}

organizada dos segmentos

dominados.

\section{político-econômico no âmbito}

dade docente, despolitizando o processo formativo em consonância com o ideário conservador em curso ou, em última instância, ampliando o potencial de a politização transcorrer por vieses moralistas. O projeto dos setores dominantes por uma escola neutra - característica da "[...] pós-modernidade reacionária [...]"14 (FREIRE, 1994, p. 112) - passa, sobretudo na presente quadra histórica, a ser substituído por um programa educacional conservador e antidemocrático. A defesa da educação para todos cede espaço para a ideologia todos pela educação. Quadro complexo passível de alteração somente a partir da mobilização, da resistência e de novas propostas dos trabalhadores e da juventude.

Nesse sentido, a luta pela política de educação pública e de qualidade, em condições que o capitalismo não é capaz ou tem o interesse de realizá-la - expressão das disputas políticas sobre os mecanismos de alcance aos direitos sociais -, pode adquirir um novo sentido crítico e contornos anticapitalistas. A desigualdade do poder político-econômico no âmbito das instituições educacionais e da política de educação contém em si a substância para converter-se em resistência e em reivindicação organizada dos segmentos dominados. Constituindo, assim, uma determinada expressão da questão social que passa a fazer parte da agenda política pública. Exemplo concreto disso foi a amostra do renovado fôlego político do movimento estudantil dada, em âmbito nacional, nos anos de 2015 e 2016.

A mobilização secundarista teve início na capital de São Paulo ${ }^{15}$, contrária ao projeto de reorganização escolar proposto pelo governo estadual, e se espraiou rapidamente pelo interior e por grande parte do País. De acordo com Eloy (2016), por volta de 600 escolas foram ocupadas por estudantes nesse período em diferentes $\operatorname{estados}^{16}$. "A ocupação das escolas paulistas do fim de 2015 foi a mobilização estudantil exclusivamente secundarista mais bem-sucedida da história." (OSHIMA; MORRONE, 2017). No Rio de Janeiro, o quantitativo foi superior a setenta, tendo dentre suas principais reivindicações melhorias na infraestrutura das unidades escolares, mudanças no sistema de ensino, apoio à mobilização de professores em greve por reajuste salarial, legitimação da eleição para diretor das unidades e outros temas relacionados à gestão democrática (ELOY, 2016).

Os estudantes brasileiros se referenciaram em experiências como a chilena, que teve destaque em 2006 com os secundaristas e em 2011/2012 com os universitários. Recorrendo à tática de autogestão, os estudantes brasileiros - com o apoio de familiares, professores, intelectuais e movimentos sociais - implementaram temporariamente nas escolas aulas e oficinas de conteúdo político-acadêmico convergentes com seus interesses, além da auto-organização coletiva e horizontalizada do trabalho na segurança, na limpeza, no refeitório e de atividades culturais e esportivas. Aproximando-se, assim, em certos aspectos do conceito de ocupação da escola, notadamente presente em experiências pedagógicas promovidas em escolas organizadas pelo Movimento dos Trabalhadores Rurais Sem Terra (MARTINS, 2011).

O Estado, ao reprimir o movimento secundarista através da força policial e judiciária, potencializou a solidariedade já em curso dos apoiadores. A mobilização fez o governo paulista, em 60 dias, recuar, abrir 
o diálogo com os estudantes organizados e, por fim, suspender sua proposta inicial de reorganização que pretendia fechar 94 escolas, superlotar salas de aula, reduzir o número de profissionais e extinguir turnos e modalidades de ensino.

Alguns dos resultados das ocupações no Rio de Janeiro foi a realização de audiências de conciliação entre estudantes e representantes da Secretaria Estadual de Educação, com a presença da Defensoria Pública, para tratar do calendário de negociação sobre os temas da pauta de reivindicações. A exigência de eleições para diretores das escolas públicas foi acatada e a Justiça decretou que as escolas ocupadas retomassem as aulas (ELOY, 2016). Conforme Ana Paula Corti, professora do Instituto Federal de educação, Ciência e Tecnologia de São Paulo e pesquisadora sobre Ensino Médio e Juventude, "Foi uma ação direta, quase uma desobediência civil, baseada no contato com movimentos análogos fora do país [...]” (ELOY, 2016). Além de vitórias referentes a conquistas mensuráveis, outro saldo positivo foi, inegavelmente, o capital político produto dessas mobilizações que ficou como legado para o movimento estudantil e, de alguma maneira, para a luta geral contemporânea dos trabalhadores.

No contexto das reivindicações sociais por maior orçamento voltado para a política de educação, o Fórum Nacional de Defesa da Educação Pública, no início dos anos 2010, rearticulou progressivamente suas atividades. Em 2014, o FNDEP organizou o Encontro Nacional de Educação (ENE), no Rio de Janeiro (RJ), com ampla participação e ênfase na luta pelos $10 \%$ do PIB para a educação pública, já! O Encontro apontou a importância do debate de temas como o da democratização nos processos de eleição de diretores de escolas, a ampliação da participação da comunidade na gestão escolar e da sociedade civil na definição das políticas educacionais, além da retirada imediata de qualquer força policial do interior de escolas, institutos e universidades. Dois anos após, foi realizado o II ENE, em Brasília (DF), com o tema principal Por um projeto de educação classista e democrático. No relatório final deste Encontro, em seu eixo sobre gestão, afirma-se que:

[...] o II ENE concluiu que é necessário avançar no debate de democracia e autonomia nas instituições públicas de educação. Para isso, é importante pautarmos a paridade na participação dos conselhos consultivos e deliberativos, e também na participação do peso da votação/consulta para eleição dos diretores de escola, assim como de reitorias. O debate de autonomia e democracia é fundamental, neste momento de aprofundamento dos ataques e cortes na educação para aceleração de implementação de um projeto de precarização, sucateamento e privatização da creche à pós-graduação. [...] Em tempos de ataques às liberdades democráticas, a exemplo da "escola sem partido", a luta pela democracia e de uma gestão democrática nas instituições públicas de educação se coloca como central na luta por um projeto classista e democrático de educação. (COMITÊ NACIONAL EM DEFESA DOS 10\% DO PIB PARAAEDUCAÇÃO JÁ!, 2016, grifo nosso).

Seguindo deliberação do II ENE e em resposta principalmente às investidas da organização Escola sem Partido, outro exemplo atual de luta coletiva pela política de educação pública com contornos anticapitalistas foi a organização da Frente Nacional Escola Sem Mordaça. O movimento, constituído na interseção com diversas entidades e coletivos do campo progressista, se propõe a constituir um polo de resistência - via forte incidência no parlamento - no enfrentamento ao avanço conservador no âmbito das escolas.

Cite-se também os ataques recentes às universidades públicas, seja via cortes no seu orçamento sob a orientação do Banco Mundial, seja por meio de grupelhos protofascistas promovendo violência contra negros, LGBTs e militantes de esquerda nos campi. Um caso sintomático foi o ato de vandalismo ocorrido na Universidade de Brasília (UnB), em outubro de 2018, onde livros sobre direitos humanos foram rasgados na biblioteca ${ }^{17}$.

Seja ainda através da tentativa de veto do, à época, ministro da Educação, ao oferecimento de disciplina intitulada $O$ Golpe de 2016 e o futuro da democracia no Brasil, também na UnB. Em resposta ao posicionamento autoritário do MEC, mais de quarenta universidades brasileiras passaram a oferecer cursos sobre o tema, bem como a Universidad de los Andes, em Bogotá, e a Universidad Nacional Autónoma de México, na Cidade do México.

No Rio de Janeiro, a ofensiva do governo estadual contra a UERJ - atrasando por meses salários, bolsas e verbas de custeio e manutenção da instituição - obrigou seus movimentos sindicais e estudantis a reagirem na intensidade necessária. Além da Universidade ter conseguido retomar suas atividades acadêmicas, a luta travada por seus trabalhadores e estudantes tornou-se referência nacional de resistência. De acordo com Saviani (2016, p. 391), a resistência na atual conjuntura brasileira implica dois requisitos principais e mediados entre si: “[...] a) que seja coletiva, pois as resistências individuais não têm força para se contrapor ao poder dominante [...]; b) que seja propositiva, isto é, que seja capaz de apresentar alternativas às medidas do governo". Preocupações incontornáveis ao exercício profissional alinhado com a transformação anticapitalista no âmbito educacional, seja ou não de assistentes sociais. 


\section{Considerações finais}

As lutas sociais comprometidas com a emancipação humana são lutas políticas intrinsecamente articuladas aos condicionantes do trabalho e aos movimentos de resistência e de superação de tais condicionantes, na relação unitária entre política e economia. É legítimo concluir, portanto, que a luta pela política educacional, sob as condições político-econômicas atuais em que o capitalismo monopolista não irá realizá-la, adquire um novo sentido crítico e contornos anticapitalistas a partir do momento que tem em si o compromisso orgânico com o fortalecimento de uma contra-hegemonia educacional e cultural e, nesta esteira, com a substantiva socialização do poder político-econômico.

A perspectiva reformista detida aos limites do escolanovismo, impressa em boa parte das lutas educacionais ao longo da história brasileira, não tende a denotar, espontânea e mecanicamente, um caráter anticapitalista. O seu clímax possível é - considerando as particularidades da formação social no País - uma modernização que angarie direitos para as maiorias, mas não capaz de alterar a conservação da ordem. Contundo, trata-se de um ponto máximo, mesmo limitado por essência, inalcançável em uma conjuntura na qual a contrarreforma de direitos, quando não a sua plena supressão, é parte inexorável do projeto dominante em curso.

Independente da atual fase do neoliberalismo, a burguesia - tendo em vista seu projeto de desenvolvimento em um capitalismo periférico e dependente - jamais planejou efetivar a educação pública como um direito social universal, democrático e de qualidade. Ou seja, considerando ainda que no capitalismo brasileiro os direitos sociais tendem a perder para a coerção sua centralidade na manutenção da hegemonia, nunca foi possivel realizar a política educacional no Brasil tal como prevê a lei. E esse fato histórico, decerto, não atribui a todas as lutas progressistas uma dimensão anticapitalista por natureza.

Pelo contrário. Reforça que a defesa da educação pública apenas confronta as bases do capital quando tem como objetivos, na sua teleologia mais ampla, o adensamento de uma contra-hegemonia plena no plano ético-político e a superação substantiva da ordem atual. Assim, "[...] acreditar que estão dadas, nesta sociedade, as condições para o exercício pleno da prática educativa é assumir uma atitude idealista. Entretanto, em relação às condições da prática política tal atitude resulta realista [ou, na pior das hipóteses, otimista]" (SAVIANI, 1989, p. 96).

Ao Serviço Social extrapola a necessidade de pensar, exclusiva à profissão, sua inserção atual na política educacional. O exercício profissional, dialeticamente, condiciona e é condicionado pelas disputas político-econômicas em torno da democratização da política de educação brasileira. Seu compromisso ético com um "posicionamento em favor da equidade e justiça social, que assegure universalidade de acesso aos bens e serviços relativos aos programas e políticas sociais, bem como sua gestão democrática" (CONSELHO FEDERAL DE SERVIÇO SOCIAL, 2012, p. 23, grifo nosso) exige não somente a precisa leitura da realidade social.

Nesse sentido, coloca-se como imperativo a assistentes sociais a apropriação crítica, cada vez mais, da categoria democracia enquanto processos de disputa pela socialização do poder político-econômico. Dentro e fora das instituições educacionais. Portanto, a luta social em defesa da política de educação no Brasil, sob as atuais condições impostas pelo capitalismo, adquire um novo sentido crítico e contornos anticapitalistas quando alinhada - no discurso e na prática - com a tendência de ruptura com a educação hegemônica que considera o processo de democratização escolar em suas várias dimensões, contemplando a defesa das garantias de acesso, de permanência e de qualidade do ensino, bem como reivindica profundas alterações na esfera pedagógica. $\mathrm{O}$ fato de ser uma tarefa difícil não exime a responsabilidade de cumpri-la.

\section{Referências}

ALGEBAILE, E. Escola sem Partido: o que é, como age, para que serve. In: FRIGOTTO, G. (org.). Escola “sem” partido: esfinge que ameaça a educação e a sociedade brasileira. Rio de Janeiro: Laboratório de Políticas Públicas, 2017. p. 63-74.

AUDI, A. Novo ministro da educação terá orçamento que pode fazer fortuna a membros do governo - incluindo o escola sem partido. The Intercept Brasil, 29 nov. 2018. Disponível em: https://theintercept.com/2018/11/23/escola-sem-partido-interesses-ministro-educacao. Acesso em: 14 dez. 2018.

BRASIL. Lei $n^{\circ} 11.645$, de 10 de Março de 2008. Altera a Lei no 9.394, de 20 de dezembro de 1996, modificada pela Lei ${ }^{\circ} 10.639$, de 9 de janeiro de 2003, que estabelece as diretrizes e bases da educação nacional, para incluir no currículo oficial da rede de ensino a obrigatoriedade da temática "História e Cultura Afro-Brasileira e Indígena”. Brasília, DF: Presidência da República, [2008]. Disponível em: http://www.planalto.gov.br/ccivil_03/_ato2007-2010/2008/lei/111645.htm.Acesso em: 18 jun. 2019.

BRASIL. Lei $n^{\circ}$ 13.415/2017, de 17 de Fevereiro de 2017. Altera as Leis n 9.394, de 20 de dezembro de 1996, que estabelece as diretrizes e bases da educação nacional, e 11.494, de 20 de junho 2007, que regulamenta o Fundo de Manutenção e Desenvolvimento da Educação Básica e de Valorização dos Profissionais da Educação, a Consolidação das Leis do Trabalho - CLT, aprovada pelo Decreto-Lei $n^{\circ} 5.452$, de $1^{\circ}$ de maio de 1943, e o Decreto-Lei ${ }^{\circ}$ 236, de 28 de fevereiro de 1967; revoga a Lei ${ }^{\circ} 11.161$, de 5 de 
agosto de 2005; e institui a Política de Fomento à Implementação de Escolas de Ensino Médio em Tempo Integral. Brasília, DF: Presidência da República, [2017]. Disponível em: http://www.planalto.gov.br/ccivil_03/_Ato2015-2018/2017/Lei/L13415.htm. Acesso em: 18 jun. 2019.

BRASIL. Câmara dos Deputados. Projeto de Lei PL $n^{\circ} 7180 / 2014$. Altera o art. $3^{\circ}$ da Lei nº 9.394, de 20 de dezembro de 1996. Brasília, DF, 24 fev. 2014. Disponível em: https://www.camara.leg.br/proposicoesWeb/fichadetramitacao?idProposicao=606722.Acesso em: 18 jun. 2019.

CAMPOS, A. M.; MEDEIROS, J; RIBEIRO, M. M. Escolas de luta. São Paulo: Veneta, 2016.

CONSELHO FEDERAL DE SERVIÇO SOCIAL. Código de ética do/a assistente social. In: Código de ética do/a assistente social: lei nº 8.662/93. 10 ed. Brasília, DF: Conselho Federal de Serviço Social, 2012, p. 23-42.

COMITÊ NACIONAL EM DEFESA DOS 10\% DO PIB PARA A EDUCAÇÃO JÁ! Relatório final do II Encontro Nacional de Educação. Brasília, DF, jul. 2016. Disponível em: http://www.cressrj.Org.br/site/wp-content/uploads/2016/07/relatocc81 rio-ii-ene.pdf. Acesso em: 15 jun. 2018.

ELOY, D. As ocupações estudantis e a gestão democrática no ensino médio. Gestão Escolar, 21 dez. 2016. Disponível em: https:// gestaoescolar.Org.br/conteudo/1650/as-ocupacoes-estudantis-e-a-gestao-democratica-no-ensino-medio. Acesso em: 20 jan. 2017.

FERNANDES, F. A revolução burguesa no Brasil: ensaio de interpretação sociológica. 5. ed. São Paulo: Globo, 2006.

FREIRE, P. Cartas a Cristina. Rio de Janeiro: Paz e Terra, 1994.

FRIGOTTO, G. Os circuitos da história e o balanço da educação no Brasil na primeira década do século XXI. Revista Brasileira de Educação, Rio de Janeiro, v. 16, n. 46, p. 235-274, jan./abr. 2011.

FRIGOTTO, G. A gênese das teses do Escola sem Partido: esfinge e ovo da serpente que ameaçam a sociedade e a educação. In: FRIGOTTO, G. (org.). Escola "sem" partido: esfinge que ameaça a educação e a sociedade brasileira. Rio de Janeiro: Laboratório de Políticas Públicas, 2017.p. 17-34.

LEHER, R. 25 anos de educação pública: notas para um balanço do período. In: GUIMARÃES, C.; BRASIL, I.; MOROSINI, M. V. (org.). Trabalho, educação e saúde: 25 anos de formação politécnica no SUS. Rio de Janeiro: Escola Politécnica de Saúde Joaquim Venâncio, 2010. p. 29-72.

MARQUES, M.; CARVALHO, L. Livro de direitos humanos são rasgados na biblioteca da UnB. G1. Brasília, DF, 4 out. 2018. Disponível em: https://g1.globo.com/df/distrito-federal/noticia/2018/10/04/livros-de-direitos-humanos-sao-rasgados-na-biblioteca-daunb.ghtml. Acesso em: 10 out. 2018.

MARTINS, F. J. Ocupação da escola: uma categoria em construção. Cascavel: EDUNIOESTE, 2011.

MORAES, L. Para pensar a "reforma” do ensino médio. Junho Blog, 25 set. 2016. Disponível em: http://blogjunho.com.br/para-pensara-reforma-do-ensino-medio. Acesso em: 16 jun. 2018.

MOREIRA, C. F. N.; RUIZ, J. L. de S. "Escola sem partido": notas sobre educação e direitos humanos. In: SEMINÁRIO INTERNACIONAL: DIREITOS HUMANOS, VIOLÊNCIA E POBREZA: A SITUAÇÃO DE CRIANÇAS E ADOLESCENTES NA AMÉRICA LATINA HOJE, 6., 2016, Rio de Janeiro. Anais [...]. Rio de Janeiro: Rede Sirius, 2016. Disponível em: http:// www.proealc.etc.br/VI_SEMINARIO/assets/pdfs/gtvi/Carlos\%20Felipe\%20Nunes\%20Moreira\%20et\%20al\%20GT06.pdf. Acesso em: 19 jun. 2019.

OSHIMA, F. Y.; MORRONE, B. O legado de ocupação nas escolas. Época, 5 fev. 2017. Disponível em: https://epoca.globo.com/ educacao/noticia/2017/02/o-legado-das-ocupacoes-nas-escolas.html. Acesso em: 23 abr. 2018.

SAVIANI, D. Escola e democracia: teorias da educação, curvatura da vara, onze teses sobre educação e política. 21. ed. São Paulo: Cortez, 1989.

SAVIANI, D. O vigésimo ano da LDB: as 39 leis que a modificaram. Retratos da Escola, Brasília, v. 10, n. 19, p. 379-392, jul./dez. 2016.

\section{Notas}

1 [...] tais como: retomada, ainda que de forma problemática, da agenda do desenvolvimento; alteração substantiva da política externa e da postura perante as privatizações; recuperação, mesmo que relativa, do Estado na sua face social; diminuição do desemprego aberto [...]; aumento real do salário mínimo (ainda que permaneça mínimo); relação distinta com os movimentos sociais [...]; e ampliação intensa de políticas e programas direcionados à grande massa não organizada que vivia abaixo da linha da pobreza ou num nível elementar de sobrevivência e consumo. (FRIGOTTO, 2011, p. 240).

2 Através do Programa de Reestruturação das Universidades Federais (REUNI).

3 Através do Programa Universidade para Todos (ProUni) e do Fundo de Financiamento ao Estudante do Ensino Superior (FIES).

4 Fórum Nacional de Defesa da Escola Pública.

5 Trata-se do Plano Nacional de Educação elaborado e proposto pela sociedade civil ao governo, no qual apresentava, dentre outros itens, a defesa da aplicação de $10 \%$ do Produto Interno Bruto nesta política.

6 Entre as medidas de maior impacto do PDE está a instauração, após o fim do Fundef, de um novo mecanismo de financiamento, o Fundo de Manutenção e Desenvolvimento da Educação Básica e de Valorização dos Profissionais da Educação (Fundeb), conceitualmente mais interessante do que o fundo anterior [...] [e que incorporou a educação infantil e o ensino médio, antes não contemplados]. Entretanto, o financiamento seguiu 
sendo um gargalo, em virtude da reduzida participação do governo federal na capitalização do novo Fundo, tornando pouco efetivos os avanços conceituais (LEHER, 2010, p. 59).

7 Miguel Nagib é advogado, procurador do município de São Paulo e coordenador do Escola sem Partido.

8 A saber: http://www.escolasempartido.org/.

9 Projeto de lei de autoria do deputado federal Erivelton Santana (PATRI-BA). Apesar do arquivamento via a ação de resistência de setores organizados da sociedade civil, projetos semelhantes já foram aprovados em algumas cidades - Araçatuba e Pedreira (SP), por exemplo - e suspensos pela Justiça em outras - como no caso de São José do Rio Preto (SP) - ou não aprovados nas Câmaras locais - vide Curitiba (PR) e Araraquara (SP). Projetos de lei de mesma inspiração, como aqueles contrários à chamada ideologia de gênero nas escolas, também têm sido apresentados pelo País e obstaculizado a partir da ação política de coletivos progressistas, como ocorrido em Niterói (RJ).

10 Foge ao escopo deste trabalho debater a legalidade ou não do processo institucional-parlamentar ocorrido em 2016. Fato esse que não contradiz o acordo com as caracterizações que o definem como golpe.

11 Pautada na Base Nacional Comum Curricular que, conforme definido na Lei de Diretrizes e Bases da Educação (LDB), deve nortear os currículos dos sistemas e redes de ensino, como também as propostas pedagógicas de todas as escolas públicas e privadas no âmbito da Educação Básica.

12 Lei $^{\circ}$ 11.645/2008(BRASIL, [2008]).

13 Nesta estrutura, o MEC representa o órgão executivo e coordenador das políticas nacionais do Sistema Nacional de Educação, e os Conselhos de Educação (nacional, estaduais e municipais) têm caráter normativo, deliberativo e fiscalizador das políticas de Estado. O FNE, por sua vez, se constituiu pela representação dos segmentos sociais voltados à educação, tendo como responsabilidade a organização da Conae e o acompanhamento da tramitação do Plano Nacional de Educação, principalmente.

14 "A pós-modernidade reacionária vem tendo certo êxito na sua propaganda ideológica ao proclamar o sumiço das ideologias, a emersão de uma nova história sem classes sociais, portanto sem interesses antagônicos, sem luta, ao apregoar não haver por que continuarmos a falar em sonho, em utopia, em justiça social”. (FREIRE, 1994, p. 112).

15 Para um registro das ocupações secundaristas em São Paulo, elaborado a partir do ponto de vista dos estudantes, ver Escolas de Luta, de autoria de Campos, Medeiros e Ribeiro (2016).

16 O número (total e parcial) de escolas ocupadas pode variar dependendo da fonte consultada.

17 Ver Marques e Carvalho (2018).

\section{Carlos Felipe Nunes Moreira}

felipe_pito@yahoo.com.br

Doutor em Serviço Social pelo Programa de Pós-Graduação em Serviço Social da Faculdade de Serviço Social da Universidade do Estado do Rio de Janeiro (UERJ)

Professor Assistente na Faculdade de Serviço Social da Universidade do Estado do Rio de Janeiro (UERJ)

\section{UERJ}

Rua São Francisco Xavier, 524, Maracanã, Rio de Janeiro/RJ - CEP: 20559-900

\author{
Agradecimentos \\ Não se aplica. \\ Agência financiadora \\ Não se aplica.
}

Contribuições das autoras

Não se aplica.
Aprovação por Comitê de Ética e consentimento para participação

Não se aplica.

Consentimento para publicação

Não se aplica.

Conflito de interesses

Não há conflito de interesses. 